\title{
Dietary total antioxidant capacity is inversely related to central adiposity as well as to metabolic and oxidative stress markers in healthy young adults
}

Helen Hermana M Hermsdorff', Blanca Puchau ${ }^{1}$, Ana Carolina P Volp², Kiriaque BF Barbosa ${ }^{3}$, Josefina Bressan ${ }^{4}$, M Ángeles Zulet ${ }^{1}$ and J Alfredo Martínez ${ }^{1 *}$

\begin{abstract}
Background: Dietary total antioxidant capacity (TAC) has been assumed as a useful tool to assess the relationship between the cumulative antioxidant food capacity and several chronic disorders. The aim of this cross-sectional study was to investigate the potential relationships of dietary TAC with adiposity, metabolic and oxidative stress markers in healthy young adults.

Methods: This study enrolled 266 healthy subjects (105 men/ 161 women; $22 \pm 3$ years-old; $22.0 \pm 2.7 \mathrm{~kg} / \mathrm{m}^{2}$ ). Dietary intake, anthropometry, blood pressure, lifestyle features, and biochemical data were assessed with validated procedures.

Results: In linear regression analyses, dietary TAC values were inversely associated with glycemia, total cholesterol: $\mathrm{HDL}-\mathrm{C}$ ratio, triglycerides and oxidized-LDL concentrations, and positively associated with HDL-C concentrations, independently of gender, age, smoking status, physical activity, vitamin use supplement, waist circumference, energy intake, fatty acid intake. In addition, plasma TAC was negatively correlated with ox-LDL concentrations $(r=$ $-0.20, P=0.003)$, independently of the assessed confounding variables. Finally, dietary TAC values were inversely related to waist circumference values $(r=-0.17, P=0.005)$ as well as to lower mild central obesity occurrence (waist circumference $\geq 80 / 94 \mathrm{~cm}$ for women/ men, respectively).

Conclusion: Dietary TAC values are inversely associated with glucose and lipid biomarkers as well as with central adiposity measurements in healthy young adults, indicating dietary TAC as a useful tool to assess the health benefits of cumulative antioxidant capacity from food intake. In addition, the independent and inverse relationships of ox-LDL concentrations with dietary and plasma TAC respectively suggest a putative role of antioxidant rich-diet in the link between redox state and atherogenesis at early stage.
\end{abstract}

Keywords: Antioxidants, Central obesity, ox-LDL, Oxidative stress, Arteriosclerosis

\section{Background}

Dyslipidemias and insulin resistance constitute major risk factors of cardiovascular diseases (CVD) and related-features [1]. Furthermore, oxidative stress impairment or altered antioxidant status have been suggested as pivotal keys in the onset of certain chronic

\footnotetext{
*Correspondence: jalfmtz@unav.es

'Department of Nutrition, Food Science, Physiology and Toxicology,

University of Navarra. Pamplona, Spain

Full list of author information is available at the end of the article
}

diseases such as metabolic syndrome (MS), type 2 diabetes and CVD $[2,3]$. In this sense, oxidized low-density lipoprotein (ox-LDL), a recognized oxidative stress marker, has been positively associated with central obesity [4], metabolic syndrome manifestations [5] and subclinical atherosclerosis [6].

In turn, dietary total antioxidant capacity (TAC) has been assessed in order to altogether capture synergic antioxidant/redox activities of single antioxidant compounds from diet [7]. Despite some authors have 
debated about the applicability of the extrapolation of dietary TAC data to its antioxidant contribution in vivo $[8,9]$, this dietary index has been a relevant tool in epidemiological studies $[10,11]$. In this sense, increased dietary TAC has been associated with higher diet quality scores [12] as well as with improved values concerning glucose metabolism [13] and inflammatory status $[14,15]$ in middle-aged people. In addition, dietary TAC has been recently associated with a lower risk for ischemic stroke in Italian cohort [16]. However, the relationship of dietary TAC with biomarkers has been only modestly investigated in young adult people $[17,18]$, which is of great interest to provide new light for early an association of overall antioxidant intake with metabolic and oxidative biomarkers in vivo. Indeed, the association between this dietary TAC and ox-LDL concentrations has not been apparently reported.

Overall, the present study assessed the potential association of dietary TAC with adiposity as well as with metabolic and oxidative stress markers in healthy young adults with emphasis on plasma ox-LDL concentrations, as a relevant oxidative stress marker and an atherosclerosis predictor.

\section{Subjects and Methods Subjects}

Participants of the current research were involved in a study of Interuniversity Cooperation between the Federal University of Viçosa (Brazil, CAPES-MECD-DGU 109/06) and the University of Navarra (Spain, PHB2005-0119-PC). Thus, a group of 266 subjects from Brazil (57 men and 66 women) and Spain (48 men and 95 women), with a mean age of $22 \pm 3$ years-old (range: 18-35 years) and a mean body mass index (BMI) of 22.0 \pm 2.7 (range: $18.5-34.9 \mathrm{~kg} / \mathrm{m}^{2}$ ), were enrolled in this study.

The volunteers were recruited through magazines, radio, web page, and intranet tools at both Universities. In the enrollement message, the age range (18-35 years old) was mentioned as well as relevant clinical information for those interested in participating in this crosssectional nutritional study. Exclusion criteria were any diagnosed organic underlying disease (gastrointestinal, kidney, liver, respiratory or heart disease), cancer, infectious and inflammatory disorders, diabetes (fasting glucose level $>126 \mathrm{mg} / \mathrm{dl}$ ), hypertension (systolic and diastolic blood pressure values $\geq 140$ and $90 \mathrm{mmHg}$, respectively), pregnancy, disorders affecting body composition (e.g. lipodystrophy and Cushing syndrome) or blood lipid-lowering treatments. Other exclusion criteria were recent follow up of diets designed for weight loss or unstable weight in the past 3 months. The present study was conducted according to the guidelines laid down in the Declaration of Helsinki and all procedures involving human subjects/patients were approved by the appropriate human research review boards at each location: Ethics Committee in Human Research of the Federal University of Viçosa (ref. $n^{\circ}$ 009/2006) and Investigation Ethics Committee of the Clínica Universidad de Navarra (ref. $n^{\circ} 79 / 2005$ ). Written informed consent was obtained from all the subjects/patients.

\section{Dietary intake assessment}

In the Brazilian sample, dietary intake information was obtained by a 3 day-record. Daily food consumption was estimated as a $3 \mathrm{~d}$-mean of portion size for each consumed food item, considering in addition to preparation (crude or cooked), and edible portions. Nutrient intake was estimated using the Diet Pro $5 \mathrm{i}^{\circledR}$ software (AS Sistemas, Viçosa, Brazil), adapted with the latest available information from the food composition tables for Brazil $[19,20]$. In the Spanish sample, dietary intake information was obtained by a semi-quantitative food frequency questionnaire with 136 food-items, which is validated for Spanish people [21,22]. Daily food consumption was estimated as frequency $\times$ portion size for each consumed food item. Nutrient intake was estimated using an ad hoc computer program specifically developed for this aim, which displays the latest available information included in the food composition tables for Spain $[23,24]$.

Furthermore, dietary TAC from dietary intake information, expressed as mmol (of Trolox equivalent)/d, was calculated by a proxy estimation previously validated to the 3 day-record as well as for the food-frequency questionnaire [18].

\section{Clinical and biochemical assessments}

Anthropometric determinations were taken using standard measurement procedures, in accordance to previously described protocols [25] as agreed by both universities participating in the study. Thus, BMI was calculated by the ratio between weight $(\mathrm{kg})$ and the squared height $\left(\mathrm{m}^{2}\right)$, which was applied to categorize normal-weight (18.5-24.9 kg/m²), overweight (25-29.9 $\mathrm{kg} / \mathrm{m}^{2}$ ), and obese (BMI $\geq 30 \mathrm{~kg} / \mathrm{m}^{2}$ ) subjects, according to the World Health Organization criteria [26]. Waist circumference was used as a central adiposity indicator, considering values higher than 80 and $94 \mathrm{~cm}$ for women and men, respectively, as an indicator of mild central obesity. Systolic and diastolic blood pressures were measured following World Health Organization guidelines [27].

Venous blood samples were drawn after a 12 h overnight fast by venipuncture. The EDTA-plasma and serum samples were separated from whole blood by centrifugation $\left(2,205 \mathrm{~g} \times 15 \mathrm{~min}\right.$ at $\left.4^{\circ} \mathrm{C}\right)$ and were frozen immediately at $-80^{\circ} \mathrm{C}$ until assay. Serum concentrations 
of triglycerides, total cholesterol (TC), high density lipoprotein-cholesterol (HDL-c), glucose and insulin were measured by standard methods as previously described $[17,25]$. Serum low-density lipoprotein-cholesterol (LDLc) and insulin resistance as HOMA-IR were calculated as described by Friedewald et al. [28] and Matthews et al. [29] equations, respectively. TC:HDL-c and LDL-c: HDL-c ratios also were calculated, since they are independent predictors of the risk for CVD [30,31]. Hypercholesterolaemia was considered as a total cholesterol concentration $\geq 200 \mathrm{mg} / \mathrm{dl}$ [1]. Plasma ox-LDL was measured using ELISA kits from Mercodia (Uppsala, Sweden), based on the mouse monoclonal antibody 4E6, which is directed against a conformational epitope in oxidized ApoB-100 [32,33]. Finally, plasma TAC was determined using a commercial colorimetric kit (Cayman Chemical Corporation, Ann Arbor, USA), based on the inhibition the oxidation of ABTS ${ }^{\circledR}$ (2,2-Azino-di-[3ethylbenzthiazoline sulphonate]) to $\mathrm{ABTS}^{\mathbb{B} \cdot+}$, which is subsequently quantified as mmol Trolox equivalent $[34,35]$.

\section{Other variable assessment}

For lifestyle variables, the participants were asked about their smoking status (never, former, or current smokers) and about vitamin supplement use (Yes/No). With respect to physical activity, the participants declared whether they took regular physical activity (Yes/No), and if so, the type and the volume of activity (h/week). To quantify the volume of activity, a metabolic equivalent (MET) index was also computed by assigning a multiple of resting metabolic rate (MET score) to each activity [36], followed by the sum over all activities to obtain a value of overall weekly MET/h as described elsewhere [37].

\section{Statistical analysis}

Results are shown as mean \pm standard deviations (SD) or median (interquartile interval), depending on the variable distribution as determined by the Shapiro-Wilk test. Non-normally distributed variables were log-transformed before statistical analyses. Dietary intakes were adjusted for the daily energy intake, while biochemical variables, when considered outcomes, were adjusted for study center, both by the residuals method, applying separate models among women and men [38]. To assess the associations of dietary TAC values with anthropometric, clinical and lifestyle characteristics of the participants, we categorized the participants by tertiles of this specific dietary index. Linear trends were assessed by assigning the median value to each tertile of dietary TAC and modeling these values as a continuous variable. Comparisons between three groups were performed by chi-square tests (categorical variables) or by one-factor ANOVA tests (continuous variables), while the post hoc Bonferroni test was used to correct the impact of multiple comparisons.

Moreover, $\beta$-coefficients and 95\% confidence intervals (CIs) were calculated in multivariate linear regression models to assess the association of dietary TAC values (independent continuous variable) with the investigated glucose and lipid biomarkers (dependent variables). Linear regression models were controlled by gender, age (years), waist circumference $(\mathrm{cm})$, daily energy intake (kcal/d), physical activity during leisure time (METshour per week), smoking status (never, former and current smokers), vitamin supplement use (Yes/ No), and monounsaturated (MUFA): saturated fatty acid (SFA) ratio intake, since these variables were considered potential confounding factors. In addition, partial correlations were established to evaluate the potential relations between dietary TAC, plasma TAC and ox-LDL concentrations as well as potential links between dietary $\mathrm{TAC}$ and waist circumference as a central adiposity indicator.

Furthermore, we used stepwise multiple regressions [38] to identify the variability impact of the consumed food-items concerning dietary TAC values of the participants of this study. Statistical analyses were performed with SPSS 15.0 software (SPSS Inc., Chicago, IL, USA) for Windows XP (Microsoft, USA). A $P$-value $<0.05$ was considered as statistically significant.

\section{Results}

Anthropometric, clinical and lifestyle characteristics were examined by tertiles of dietary TAC values (Table 1). Thus, those subjects included in the highest tertile were older subjects, had lower values for diastolic blood pressure and higher values for physical activity counts (METs), while reported higher vitamin supplement use as compared with those of the lowest tertile $(P<0.05)$. In addition, the participants included in the last tertile of dietary TAC consumption had significantly lower waist circumference values as well as lower occurrence of mild central obesity (as waist circumference $\geq$ 80 and $94 \mathrm{~cm}$ for women and men, respectively). Indeed, dietary TAC values were negatively and significantly correlated $(r=-0.17, P<0.05)$ with waist circumference values in the partial correlation adjusted for gender (Figure 1).

Moreover, those participants who were included in the third tertile of dietary TAC presented higher consumption of olive oil, fruits, vegetables, fruit juices, fish, coffee and red wine as well as higher intake values of protein, lipids, monounsaturated fatty acid (MUFA), and dietary fiber, while lower intake values for saturated fatty acid (SFA) were found as compared with subjects in the lowest tertile (Table 2). In addition, the food-groups 
Table 1 Anthropometric, clinical, and lifestyle characteristics, according to tertiles $(T)$ of energyadjusted dietary TAC $(n=266)$

\begin{tabular}{|c|c|c|c|c|}
\hline & \multicolumn{3}{|c|}{$\begin{array}{l}\text { Energy-adj. dietary TAC (mmol/ } \\
\text { d) }\end{array}$} & \multirow[b]{2}{*}{$\begin{array}{c}P- \\
\text { value }^{a}\end{array}$} \\
\hline & $\mathrm{T} 1(<1.6)$ & $\begin{array}{c}\mathrm{T} 2 \\
(1.6-5.9)\end{array}$ & $\begin{array}{c}\mathrm{T} 3 \\
(\geq 5.9)\end{array}$ & \\
\hline Participants (n) & 86 & 90 & 90 & \\
\hline Men $(n, \%)$ & $34(39.5)^{b}$ & $35(38.8)$ & $34(37.8)$ & 0.994 \\
\hline Age $(y)$ & $21 \pm 3^{e}$ & $22 \pm 3$ & $23 \pm 4$ & 0.031 \\
\hline Body mass index $\left(\mathrm{kg} / \mathrm{m}^{2}\right)$ & $21.8 \pm 3.1$ & $22.5 \pm 2.6$ & $21.9 \pm 2.4$ & 0.201 \\
\hline Waist circumference (cm) & $76.1 \pm 9.0^{e}$ & $75.5 \pm 8.1$ & $72.9 \pm 7.6$ & 0.027 \\
\hline $\begin{array}{l}\text { Overweight/ Obesity } \\
(n, \%)^{c}\end{array}$ & $11(33.3)$ & $13(39.5)$ & $9(27.3)$ & 0.731 \\
\hline $\begin{array}{l}\text { Mild central obesity }(n, \%) \\
d\end{array}$ & $12(14.0)$ & $12(13.3)$ & $2(2.2)$ & 0.014 \\
\hline $\begin{array}{l}\text { Physical activity practice } \\
(n, \%)\end{array}$ & $47(54.6)$ & $54(60.0)$ & $60(66.7)$ & 0.087 \\
\hline METs (h/ week) & $32(18 ; 59)^{e}$ & $40(20 ; 85)$ & $\begin{array}{c}98 \\
(43 ; 186)\end{array}$ & 0.037 \\
\hline $\begin{array}{l}\text { Former/ Current smoker } \\
(\mathrm{n}, \%)\end{array}$ & $14(16.9)$ & $24(26.7)$ & $26(28.9)$ & 0.106 \\
\hline $\begin{array}{l}\text { Vitamin supplement use } \\
(\mathrm{n}, \%)\end{array}$ & $10(11.6)$ & $23(25.5)$ & $28(31.1)$ & 0.031 \\
\hline $\begin{array}{l}\text { Hypercholesterolaemia } \\
(\mathrm{n}, \%)\end{array}$ & $13(39.4)$ & $8(24.2)$ & $12(36.4)$ & 0.132 \\
\hline Systolic BP (mmHg) & $110 \pm 9$ & $113 \pm 11$ & $112 \pm 10$ & 0.081 \\
\hline Diastolic BP (mmHg) & $72 \pm 8^{e}$ & $69 \pm 9$ & $66 \pm 8$ & $<0.001$ \\
\hline
\end{tabular}

${ }^{a} P$-value from one-factor ANOVA test or $\chi^{2}$ test, for continuous or categorical variables, respectively. Non-normally distributed variables were logtransformation before analyses.

${ }^{b}$ Continuous variables are presented as mean \pm SD or median (interquartile interval), while categorical variables are presented as number of the participants (percentages).

'Overweight/Obesity occurrence, according to BMI values ( $\geq 25$ and $\geq 30 \mathrm{~kg} /$ $\mathrm{m}^{2}$, respectively).

${ }^{d}$ Mild central obesity occurrence, according to waist circumference values ( $\geq$ 80 and $\geq 94 \mathrm{~cm}$ for women and men, respectively).

${ }^{e} P<0.05, T 1$ vs. T3; from the post hoc Bonferroni test for multiple comparisons.

TAC, total antioxidant capacity; MET, metabolic equivalent index; BP, blood pressure.

consumed by the participants with higher contribution to dietary TAC values were vegetables, fruits and fruit juices $\left(R^{2}=0.69\right)$. Other important contributing food items, such as olive oil, coffee, fish, and legumes, explained altogether $22 \%$ of total variability in dietary TAC. Fruits and vegetables remained as the highest contributors to dietary TAC when the analysis was performed by study center (data not shown).

Regarding the association between dietary TAC and glucose profile, dietary TAC values were inversely associated with glycemia and HOMA-IR $(P<0.05)$, independently of gender, age, waist circumference, smoking habit, physical activity counts, vitamin supplement use (Table 3). Furthermore, higher dietary TAC values were statistically associated with lower values to TC concentrations, TC:HDL-c ratio, ox-LDL and triglycerides

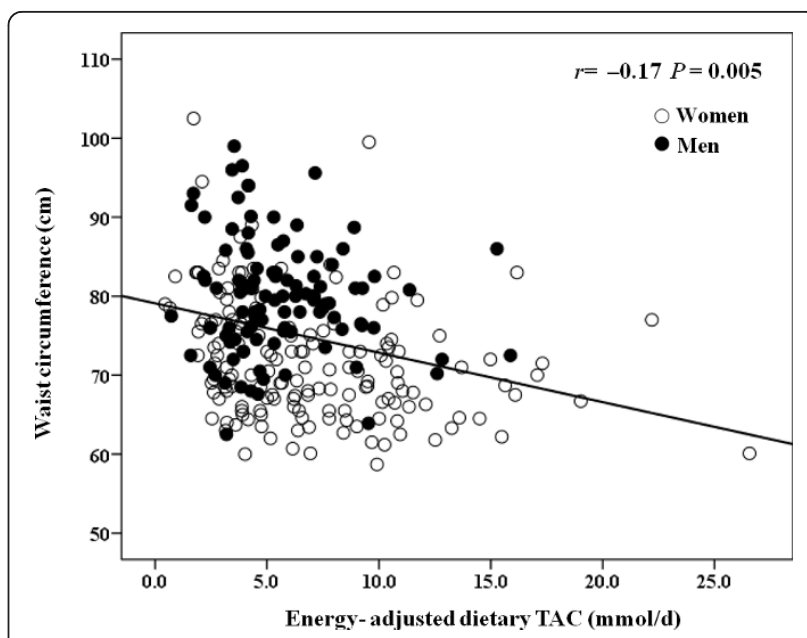

Figure 1 Association between dietary TAC and waist circumference values. $P$-value from partial correlation, adjusted for gender $(n=266)$.

concentrations as well as with higher values to HDL-c concentrations, independently of the same covariates (Table 3). Interestingly, similar outcomes are found when waist circumference $(\mathrm{cm})$ was substituted by BMI

Table 2 Food and nutrients consumption, according to tertiles (T) of energy-adjusted dietary TAC $(n=266)$

\begin{tabular}{|c|c|c|c|c|}
\hline & \multicolumn{3}{|c|}{ Energy-adj. dietary TAC (mmol/d) } & \multirow[b]{2}{*}{$P$-value ${ }^{a}$} \\
\hline & $\mathrm{T} 1(<1.6)$ & $\mathrm{T} 2(1.6-5.9)$ & $\mathrm{T} 3(\geq 5.9)$ & \\
\hline Participants (n) & 86 & 90 & 90 & \\
\hline Energy intake (kcal) & $2758 \pm 699$ & $2540 \pm 922$ & $2785 \pm 855$ & 0.108 \\
\hline Carbohydrate (\% El) & $50.5 \pm 7.9^{\mathrm{b}, \mathrm{c}}$ & $47.3 \pm 8.4^{d}$ & $44.5 \pm 8.0$ & $<0.001$ \\
\hline Protein (\%El) & $15.0 \pm 2.5^{b, c}$ & $16.5 \pm 2.7^{d}$ & $17.5 \pm 2.6$ & $<0.001$ \\
\hline Lipids (\%El) & $33.3 \pm 6.0^{b, c}$ & $36.1 \pm 6.1$ & $36.9 \pm 6.0$ & 0.002 \\
\hline MUFA (\%EI) & $6.3 \pm 4.2^{\mathrm{b}, \mathrm{c}}$ & $12.4 \pm 6.2^{d}$ & $15.7 \pm 4.5$ & 0.001 \\
\hline PUFA (\%EI) & $4.6 \pm 2.1^{c}$ & $5.5 \pm 2.7$ & $5.4 \pm 1.9$ & 0.017 \\
\hline SFA (\%El) & $12.2 \pm 3.6^{b, c}$ & $10.6 \pm 4.0^{\mathrm{d}}$ & $9.1 \pm 3.8$ & 0.003 \\
\hline Dietary fiber $(\mathrm{g} / \mathrm{d})$ & $24.2 \pm 13.2^{b}$ & $25.3 \pm 15.0$ & $29.6 \pm 12.7$ & 0.023 \\
\hline Olive oil $(\mathrm{ml} / \mathrm{d})$ & $4 \pm 16^{b, c}$ & $19 \pm 27^{d}$ & $39 \pm 33$ & $<0.001$ \\
\hline Fruits $(g / d)$ & $154 \pm 120^{b, c}$ & $245 \pm 190^{d}$ & $393 \pm 300$ & $<0.001$ \\
\hline Vegetables (g/d) & $94 \pm 68^{b, c}$ & $253 \pm 211^{d}$ & $572 \pm 395$ & $<0.001$ \\
\hline Fruit juice $(\mathrm{ml} / \mathrm{d})$ & $67 \pm 95^{b}$ & $91 \pm 122$ & $169 \pm 233$ & $<0.001$ \\
\hline Cereals (g/d) & $145 \pm 114$ & $167 \pm 104$ & $177 \pm 83$ & 0.103 \\
\hline Legumes (g/d) & $29 \pm 20$ & $28 \pm 31$ & $20 \pm 13$ & 0.127 \\
\hline Red meats $(\mathrm{g} / \mathrm{d}$ ) & $99 \pm 67$ & $96 \pm 54$ & $84 \pm 61$ & 0.214 \\
\hline Fish $(g / d)$ & $16 \pm 43^{b, c}$ & $41 \pm 52^{d}$ & $93 \pm 63$ & $<0.001$ \\
\hline Nuts $(g / d)$ & $8 \pm 10$ & $7 \pm 8$ & $15 \pm 32$ & 0.281 \\
\hline Coffee $(\mathrm{ml} / \mathrm{d})$ & $38 \pm 63^{b}$ & $59 \pm 82$ & $68 \pm 84$ & 0.028 \\
\hline Beer $(\mathrm{ml} / \mathrm{d})$ & $31 \pm 62$ & $31 \pm 49$ & $58 \pm 107$ & 0.069 \\
\hline Red wine $(\mathrm{ml} / \mathrm{d})$ & $6 \pm 5^{b}$ & $7 \pm 4^{d}$ & $50 \pm 18$ & 0.009 \\
\hline
\end{tabular}

${ }^{\mathrm{a}} P$-value from one-factor ANOVA test.

${ }^{\mathrm{b}} P<0.05, \mathrm{~T} 1$ vs. T3; ${ }^{\mathrm{C}} P<0.05, \mathrm{~T} 1$ vs. T2; ${ }^{\mathrm{d}} P<0.05, \mathrm{~T} 2$ vs. T3, from the post hoc Bonferroni test for multiple comparisons.

dietary TAC, dietary total antioxidant capacity; El, energy intake; MUFA, monounsaturated fatty acid; PUFA, polyunsaturated fatty acid; SFA, saturated fatty acid. 
Table 3 Association of dietary TAC values (as independent variable) and glucose and lipid profile (as dependent variables) in the participants of the study $(n=266)$

\begin{tabular}{|c|c|c|}
\hline \multirow[t]{2}{*}{ Dependent variables $^{a}$} & \multicolumn{2}{|c|}{ Energy-adj. dietary TAC $(\mathrm{mmol} / \mathrm{d})$ as independent variable } \\
\hline & Model $1^{\mathrm{b}}$ & Model $2^{b}$ \\
\hline Glucose (mg/dl) & $-0.002(-0.003 ;-0.001)^{c}$ & $-0.002(-0.003 ;-0.001)$ \\
\hline Insulin $(\mu \mid U / I)$ & $-0.009(-0.0180 ;-0.001)$ & $-0.006(-0.016 ; 0.003)$ \\
\hline HOMA-IR & $-0.011(-0.021 ;-0.002)$ & $-0.008(-0.019 ; 0.004)$ \\
\hline TC (mg/dl) & $0.003(0.001 ; 0.006)$ & $0.002(-0.002 ; 0.005)$ \\
\hline $\mathrm{HDL}-\mathrm{c}(\mathrm{mg} / \mathrm{dl})$ & $0.007(0.004 ; 0.010)$ & $0.005(0.001 ; 0.008)$ \\
\hline LDL-c (mg/dl) & $0.004(-0.001 ; 0.008)$ & $-0.001(-0.003 ; 0.005)$ \\
\hline TC:HDL-c ratio & $-0.004(-0.007 ;-0.001)$ & $-0.003(-0.006 ;-0.001)$ \\
\hline LDL-c:HDL-c ratio & $-0.003(-0.008 ; 0.001)$ & $-0.004(-0.008 ; 0.001)$ \\
\hline ox-LDL $(U / /)^{d}$ & $-2.772(-3.226 ;-2.318)$ & $-1.976(-2.422 ;-1.531)$ \\
\hline $\mathrm{TG}(\mathrm{mg} / \mathrm{dl})$ & $-0.013(-0.020 ;-0.007)$ & $-0.007(-0.013 ;-0.001)$ \\
\hline
\end{tabular}

${ }^{a}$ Non-normally distributed variables were log-transformed before regression analyses and, adjusted for study center by residual method.

${ }^{b}$ Model 1: multivariate linear regression adjusted for gender, age (years), waist circumference (cm), daily energy intake (kcal/d), smoking habit (never or smoker/ former), METs (h/week), and vitamin supplement use (Yes/ No). Model 2: multivariate linear regression adjusted for as model 1 plus MUFA: SFA ratio intake.

'Data are $\beta$-coefficient (95\% Confidence Interval). Bold style to significant associations.

${ }^{d} n=224$, for this variable.

TAC, total antioxidant capacity; HOMA-IR, insulin resistance index; TC, total cholesterol; HDL-c, high density lipoprotein-cholesterol; LDL-c, low density lipoproteincholesterol; ox-LDL, oxidized low density protein cholesterol; TG, triglycerides.

$\left(\mathrm{kg} / \mathrm{m}^{2}\right)$ or by mild central obesity occurrence, as categorical covariate (data not shown).

Since dietary fatty acids have been related to atherogenesis and CVD, linear regression models were also adjusted for MUFA:SFA ratio. In this case, the associations of dietary TAC values with glycemia, TC:HDL-c ratio, HDL-c, ox-LDL and triglycerides concentrations maintained the trend and the statistical significance, while its associations with insulin, HOMA-IR, and TC lost the statistical significance (Table 3). For this reason, the interaction between dietary TAC and MUFA:SFA ratio was tested, but any statistical interplay was found $(P>0.05)$.

Finally, dietary TAC values were positively related with plasma TAC concentrations in the participants of the study, although statistical significance was not identified $(r=0.11, P=0.131)$ in the partial correlation, adjusted for study center, gender, age, and energy intake. Interestingly, plasma TAC was inversely correlated with ox-LDL concentrations $(r=-0.20, P=0.003)$, independently of the study center, gender, age, energy intake, waist circumference and LDL-c concentrations (Figure 2).

\section{Discussion}

The first relevant finding of this study was the lower occurrence of mild central obesity in those individuals included in the last tertile of dietary TAC, while dietary TAC values were inversely correlated to waist circumference values in a young population. Other studies have reported an inverse association of the dietary TAC and dietary antioxidants with obesity indicators, while abdominal obesity has been associated with decreased serum antioxidants concentrations in other age groups [10,39-41]. Thus, in the line with existing literature, data from our study indicate a relationship between dietary antioxidant consumption, body fat distribution and antioxidant status in healthy young people.

In this study, the dietary TAC was also inversely associated with glucose biomarkers. This finding is in agreement with other studies that have reported an inverse relationship between dietary TAC and glucose biomarkers in young and middle-aged subjects $[13,18]$, reinforcing the hypothesis of an interactive influence between

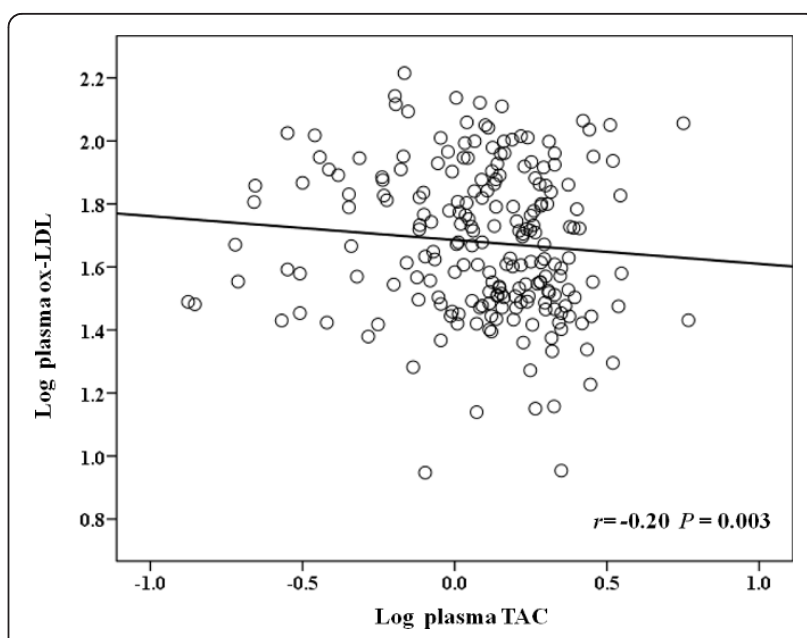

Figure 2 Association between log plasma TAC and log ox-LDL. $P$-value from partial correlation, adjusted for study center, gender, age, energy intake, waist circumference and LDL-c concentrations (n $=224)$. 
oxidative stress, pro-inflammation and insulin resistance $[2,42]$.

In turn, the association of a higher dietary TAC with lower values of some specific lipid biomarkers appears to be reported apparently for the first time in the present study. In fact, an increased consumption of antioxidantrich foods, such as fruits, vegetables, olive oil, nuts, red wine, seafood and legumes, has resulted in an improvement in the lipid profile, with increased HDL-c and decreased LDL-c and triglycerides concentrations in some intervention trial studies [43-46]. Likewise, polyphenols and carotenoids have the ability to reduce cholesterol absorption, to increase cholesterol and fecal bile excretion, to inhibit cholesterol synthesis and to stimulate the expression and activity of the LDL receptors [47]. Since these compounds might contribute to dietary TAC values, they could be related to potential hypocholesterolemic mechanisms involving the dietary healthy index. In this context, our findings suggest that dietary TAC is a reliable indicator to assess the relationship of antioxidant-food items altogether with glucose and lipid biomarkers, despite other studies could contribute to establish molecular and cellular mechanisms as well as its potential application in the treatment of chronic disorders in vivo.

Other relevant outcome of this cross-sectional study, which is also apparently reported for the first time, was the inverse and independent association of dietary TAC values with ox-LDL, a recognized oxidative stress marker and independent risk factor for MS and CVD [5,6]. In fact, a high consumption of antioxidant-rich foods might decrease oxidation in the low-density lipoprotein. On one hand, by scavenging free radicals and by sparing lipophilic antioxidant content of lipoproteins and, on the other hand by increasing the plasma TAC availability [47-50]. In this sense, the independent correlation between plasma TAC and ox-LDL concentrations observed in this study might explain, at least in part, the potential effect of dietary TAC on this oxidative stress marker. In fact, lipid-soluble antioxidants (e.g. carotenoids) are carried in LDL; therefore, an increase in the antioxidant-substrate could be reflected in higher LDL resistance to oxidation [51].

Moreover, we had previously reported an inverse association between dietary TAC values, plasma C-reactive protein and gene expression of the nuclear factorkappa- $B$, interleukin-1 receptor-1, interleukin- 6 and tumor necrosis factor-alpha [17]. Since ox-LDL is able to induce a pro-inflammatory status by the activation of the nuclear factor-kappa-B, a redox-sensitive and proinflammatory transcriptional factor [42,52], our previous and current findings suggest jointly a putative role of antioxidant rich-foods, expressed by dietary TAC values, in the link between oxidative stress and inflammation in which TAC and ox-LDL are likely interacting.
In turn, when MUFA:SFA ratio was included in the linear regression models, the prediction power of dietary TAC on glucose and lipid biomarkers was attenuated or lost in some cases (HOMA-IR, TC and triglycerides). This finding suggests potential synergistic actions of the subtype of fat intake and dietary antioxidant content in the glucose and lipid metabolism, since the replacement of SFA to MUFA resulted in an improvement in the lipid profile and glycemic control in other intervention trials [43,53-55]. Likewise, since dietary TAC values were inversely correlated to waist circumference values in this study and, body adiposity has been positively associated with pro-inflammatory and oxidative stress markers $[4,10,56,57]$, the inverse relationships of dietary TAC values with some of the investigated biomarkers could be biased by a lower central obesity among those participants with higher dietary TAC values. However, the associations between dietary TAC and the studied markers maintained the trend and the statistical significance regardless of the waist circumference, suggesting that the effects of dietary TAC on glucose and lipid profile in this study were independently from body fat distribution. In addition, our sample presented higher number of women $(60 \%)$. The hormone estrogen $(17 \beta$ estradiol in particular) has been noted to have antioxidant and antilipidemic properties [58], which might influence in the association of dietary intake with the studied biomarkers, depending on menstrual cycle status. However, we adjusted dietary total antioxidant by energy in separated models for women and men and we assessed the association of dietary TAC values with the investigated glucose and lipid biomarkers in multivariate linear regression models controlled by gender. Thus, our main study outcomes should be independent from gender and sex-hormonal effect. Moreover, estradiol concentrations have not been able to modify the oxidative and inflammation status in young women, regardless menstrual cycle phase [58].

Our study had certain limitations. First, since the nature of this study is cross-sectional, we cannot prove that the reported associations are causal, although we controlled for several potential covariates. Second, the use of different dietary assessment methods (food-frequency questionnaire and 3 day-record) by the study centers could provide differences in the information concerning dietary intake. However, both dietary assessment methods were validated to assess dietary TAC with a strong correlation between them [18]. At the same time, both dietary questionnaires have been successfully used to assess the relationship of dietary TAC values from habitual diet with biomarkers $[13,14,17,18]$. In addition, major outcomes of this study maintained the statistical significance after adjusting for study center. Finally, although the sample size is adequate from the 
standpoint of an initial association discovery, further replication in independent and larger samples would be convenient for a future translational application at a population level.

\section{Conclusion}

In this cross-sectional study, dietary TAC values are inversely associated with glucose and lipid biomarkers as well as with central adiposity in healthy young adults, indicating dietary TAC as a useful epidemiological tool to assess to health benefits of a cumulative antioxidant capacity from food intake. In addition, the independent and inverse relationships of ox-LDL concentrations with dietary and plasma TAC suggest a putative role of an antioxidant rich-diet in the link between redox state and atherogenesis at early stage.

\section{Abbreviations \\ BMI: body mass index; CVD: cardiovascular disease; HDL-C: high density lipoprotein-cholesterol; MET: metabolic equivalent index; MUFA: monounsaturated fatty acid; MS: metabolic syndrome; LDL-c: low density lipoprotein-cholesterol; ox-LDL: oxidized low density lipoprotein; SFA: saturated fatty acid; TAC: total antioxidant capacity; TC: total cholesterol.}

\section{Acknowledgements}

We wish to thank the physician Blanca E. Martínez de Morentín, the nurse Salomé Pérez, and the technician Verónica Ciaurriz as well as to the nursing assistant Elisângela Lessa for excellent technical assistance in the University of Navarra and Federal University of Viçosa, respectively. We also thank to The Capes Foundation - Ministry of Education of Brazil as well as to the Ministry of Education of Spain for the supporting the interuniversity cooperation between the Federal University of Viçosa (CAPES-MECD-DGU 109/06) and the University of Navarra (PHB-2005-0119-PC). Finally, this work was supported by the Health Department of the Government of Navarra (22/2007), the Linea Especial about Nutrition, Obesity and Health (University of Navarra LE/97), and by the Foundation for Research Support of the State of Minas Gerais (FAPEMIG- CDS 303/06).

\section{Author details}

'Department of Nutrition, Food Science, Physiology and Toxicology, University of Navarra. Pamplona, Spain. ${ }^{2}$ Department of Clinical and Social Nutrition, Federal University of Ouro Preto, Ouro Preto, Brazil. ${ }^{3}$ Nutrition Center, Federal University of Sergipe, Aracaju, Brazil. ${ }^{4}$ Department of Nutrition and Health, Federal University of Viçosa. Viçosa, Brazil.

\section{Authors' contributions}

HHMH: Design, field work, data collection, analysis, and writing of the manuscript. BP, ACPV, and KBFB: Design, field work, and data collection. JB: project leader in Brazil, design, financial management. MZ: project co-leader in Spain, design, financial management. JAM: project leader in Spain, general coordination, design, financial management, data interpretation. All authors assisted in editing the manuscript as well as they read and approved the final manuscript.

\section{Competing interests}

The authors declare that they have no competing interests.

Received: 30 May 2011 Accepted: 22 August 2011

Published: 22 August 2011

\section{References}

1. NCEP: Executive Summary of the Third Report of the National Cholesterol Education Program (NCEP) Expert Panel on Detection, Evaluation, and Treatment of High Blood Cholesterol in Adults (Adult Treatment Panel III). JAMA 2001, 285:2486-2497.
2. Pérez-Matute P, Zulet MÁ, Martínez JA: Reactive species and diabetes: counteracting oxidative stress to improve health. Curr Opin Pharmacol 2009, 9:771-779.

3. Valko M, Leibfritz D, Moncol J, Cronin MT, Mazur M, Telser J: Free radicals and antioxidants in normal physiological functions and human disease. Int J Biochem Cell Biol 2007, 39:44-84.

4. Weinbrenner T, Schroder H, Escurriol V, Fito M, Elosua R, Vila J, Marrugat J, Covas Ml: Circulating oxidized LDL is associated with increased waist circumference independent of body mass index in men and women. Am J Clin Nutr 2006, 83:30-35.

5. Holvoet P, Lee DH, Steffes M, Gross M, Jacobs DR Jr: Association between circulating oxidized low-density lipoprotein and incidence of the metabolic syndrome. JAMA 2008, 299:2287-2293.

6. Meisinger C, Baumert J, Khuseyinova N, Loewel H, Koenig W: Plasma oxidized low-density lipoprotein, a strong predictor for acute coronary heart disease events in apparently healthy, middle-aged men from the general population. Circulation 2005, 112:651-657.

7. Niki E: Assessment of antioxidant capacity in vitro and in vivo. Free Radic Biol Med 2010, 49:503-515.

8. Sies H: Total antioxidant capacity: appraisal of a concept. J Nutr 2007, 137:1493-1495.

9. Ghiselli A, Serafini M, Natella F, Scaccini C: Total antioxidant capacity as a tool to assess redox status: critical view and experimental data. Free Radic Biol Med 2000, 29:1106-1114.

10. Chrysohoou C, Panagiotakos DB, Pitsavos C, Skoumas I, Papademetriou L, Economou M, Stefanadis C: The implication of obesity on total antioxidant capacity in apparently healthy men and women: the ATTICA study. Nutr Metab Cardiovasc Dis 2007, 17:590-597.

11. Yang M, Chung SJ, Chung CE, Kim DO, Song WO, Koo SI, Chun OK: Estimation of total antioxidant capacity from diet and supplements in US adults. Br J Nutr 2011, 106:254-263.

12. Puchau B, Zulet MA, de Echavarri AG, Hermsdorff HHM, Martinez JA: Dietary total antioxidant capacity: a novel indicator of diet quality in healthy young adults. J Am Coll Nutr 2009, 28:648-656.

13. Psaltopoulou T, Panagiotakos DB, Pitsavos C, Chrysochoou C, Detopoulou P, Skoumas J, Stefanadis C: Dietary antioxidant capacity is inversely associated with diabetes biomarkers: The ATTICA study. Nutr Metab Cardiovasc Dis 2011, 21:651-567.

14. Brighenti F, Valtueña S, Pellegrini N, Ardigo D, Del Rio D, Salvatore S, Piatti P, Serafini M, Zavaroni I: Total antioxidant capacity of the diet is inversely and independently related to plasma concentration of highsensitivity C-reactive protein in adult Italian subjects. Br J Nutr 2005, 93:619-625.

15. Detopoulou P, Panagiotakos DB, Chrysohoou C, Fragopoulou E, Nomikos T, Antonopoulou S, Pitsavos C, Stefanadis C: Dietary antioxidant capacity and concentration of adiponectin in apparently healthy adults: the ATTICA study. Eur J Clin Nutr 2009, 64:161-168.

16. Del Rio D, Agnoli C, Pellegrini N, Krogh V, Brighenti F, Mazzeo T, Masala G, Bendinelli B, Berrino F, Sieri S, et al: Total antioxidant capacity of the diet is associated with lower risk of ischemic stroke in a large Italian cohort. J Nutr 2011, 141:118-123.

17. Hermsdorff HHM, Zulet MA, Puchau B, Martínez JA: Fruit and vegetable consumption and proinflammatory gene expression from peripheral blood mononuclear cells in young adults: a translational study. Nutr Metab (Lond) 2010, 7:42.

18. Puchau B, Zulet MA, de Echavarri AG, Hermsdorff HHM, Martinez JA: Dietary total antioxidant capacity is negatively associated with some metabolic syndrome features in healthy young adults. Nutrition 2010, 26:534-541.

19. Tabela Brasileira de Composição de Alimentos (TACO) Versão II. [http:// www.unicamp.br/nepa/taco/contar/taco_versao2.pdf].

20. Philippi ST: Tabela de composição de alimentos: Suporte para decisão nutricional. 2 edition. São Paulo; 2002.

21. Fernández-Ballart JD, Pinol JL, Zazpe I, Corella D, Carrasco P, Toledo E, Pérez-Bauer M, Martínez-González MA, Salas-Salvadó J, Martín-Moreno JM: Relative validity of a semi-quantitative food-frequency questionnaire in an elderly Mediterranean population of Spain. Br J Nutr 2010, 103:1808-1816.

22. Martín-Moreno JM, Boyle P, Gorgojo L, Maisonneuve P, FernandezRodriguez JC, Salvini S, Willett WC: Development and validation of a food frequency questionnaire in Spain. Int J Epidemiol 1993, 22:512-519. 
23. Mataix J: Tabla de composición de alimentos. 5 edition. Granada: Universidad de Granada; 2009

24. Moreiras O, Carbajal A, Cabrera L, Cuadrado C: Tabla de composición de alimentos. 10 edition. Madrid: Ediciones Pirámide; 2006.

25. Hermsdorff HHM, Zulet MA, Puchau B, Bressan J, Martínez JA: Association of retinol-binding protein- 4 with dietary selenium intake and other lifestyle features in young healthy women. Nutrition 2009, 25:392-399.

26. WHO: World Health Organization. Programme of Nutrition, Family and Reproductive Health. Obesity. Preventing and managing the global epidemic. Report of a WHO consultation on obesity. Geneva; 1998.

27. Whitworth JA, Chalmers J: World health organisation-international society of hypertension (WHO/ISH) hypertension guidelines. Clin Exp Hypertens 2004, 26:747-752.

28. Friedewald WT, Levy RI, Fredrickson DS: Estimation of the concentration of low-density lipoprotein cholesterol in plasma, without use of the preparative ultracentrifuge. Clin Chem 1972, 18:499-502.

29. Matthews DR, Hosker JP, Rudenski AS, Naylor BA, Treacher DF, Turner RC: Homeostasis model assessment: insulin resistance and beta-cell function from fasting plasma glucose and insulin concentrations in man. Diabetologia 1985, 28:412-419.

30. Hsia SH, Pan D, Berookim P, Lee ML: A population-based, cross-sectional comparison of lipid-related indexes for symptoms of atherosclerotic disease. Am J Cardiol 2006, 98:1047-1052.

31. Ingelsson E, Schaefer EJ, Contois JH, McNamara JR, Sullivan L, Keyes MJ, Pencina MJ, Schoonmaker C, Wilson PW, D'Agostino RB, Vasan RS: Clinical utility of different lipid measures for prediction of coronary heart disease in men and women. JAMA 2007, 298:776-785.

32. Holvoet $P$, Donck J, Landeloos M, Brouwers E, Luijtens K, Arnout J, Lesaffre E, Vanrenterghem Y, Collen D: Correlation between oxidized low density lipoproteins and von Willebrand factor in chronic renal failure. Thromb Haemost 1996, 76:663-669.

33. Holvoet P, Macy E, Landeloos M, Jones D, Jenny NS, Van de Werf F, Tracy RP: Analytical performance and diagnostic accuracy of immunometric assays for the measurement of circulating oxidized LDL. Clin Chem 2006, 52:760-764

34. Miller NJ, Rice-Evans C, Davies MJ, Gopinathan V, Milner A: A novel method for measuring antioxidant capacity and its application to monitoring the antioxidant status in premature neonates. Clin Sci (Lond) 1993, 84:407-412.

35. Miller NJ, Rice-Evans CA: Factors influencing the antioxidant activity determined by the ABTS.+ radical cation assay. Free Radic Res 1997 26:195-199.

36. Ching PL, Willett WC, Rimm EB, Colditz GA, Gortmaker SL, Stampfer MJ: Activity level and risk of overweight in male health professionals. Am J Public Health 1996, 86:25-30.

37. Martínez-González MA, López-Fontana C, Varo Jل Jánchez-Villegas A, Martínez JA: Validation of the Spanish version of the physical activity questionnaire used in the Nurses' Health Study and the Health Professionals' Follow-up Study. Public Health Nutr 2005, 8:920-927.

38. Willett WC: Nutritional Epidemiology. 2 edition. New York: Oxford University Press; 1998.

39. Canoy D, Wareham N, Welch A, Bingham S, Luben R, Day N, Khaw KT: Plasma ascorbic acid concentrations and fat distribution in 19,068 British men and women in the European Prospective Investigation into Cancer and Nutrition Norfolk cohort study. Am J Clin Nutr 2005, 82:1203-1209.

40. Puchau B, Ochoa MC, Zulet MA, Marti A, Martínez JA, Members G: Dietary total antioxidant capacity and obesity in children and adolescents. Int Food Sci Nutr 2010, 61:713-721.

41. Zulet MA, Puchau B, Hermsdorff HHM, Navarro C, Martínez JA: Vitamin A intake is inversely related with adiposity in healthy young adults. J Nutr Sci Vitaminol 2008, 54:347-352.

42. Rains JL, Jain SK: Oxidative stress, insulin signaling, and diabetes. Free Radic Biol Med 2011, 50:567-575.

43. Estruch R, Martínez-González MA, Corella D, Salas-Salvadó J, Ruiz-Gutiérrez V Covas MI, Fiol M, Gómez-Gracia E, López-Sabater MC, Vinyoles E, et al: Effects of a Mediterranean-style diet on cardiovascular risk factors: a randomized trial. Ann Intern Med 2006, 145:1-11.

44. Hermsdorff HHM, Zulet MA, Abete I, Martínez JA: A legume-based hypocaloric diet reduces proinflammatory status and improves metabolic features in overweight/obese subjects. Eur J Nutr 2011 50:61-69.
45. Ros E, Nuñez I, Pérez-Heras A, Serra M, Gilabert R, Casals E, Deulofeu R: A walnut diet improves endothelial function in hypercholesterolemic subjects: a randomized crossover trial. Circulation 2004, 109:1609-1614

46. Silver HJ, Dietrich MS, Niswender KD: Effects of grapefruit, grapefruit juice and water preloads on energy balance, weight loss, body composition, and cardiometabolic risk in free-living obese adults. Nutr Metab (Lond) 2011, 8:8.

47. Saura-Calixto F: Dietary fiber as a carrier of dietary antioxidants: an essential physiological function. J Agric Food Chem 2011, 59:43-49.

48. Barbosa KB, Bressan J, Zulet MA, Martínez-Hernández JA: [Influence of dietary intake on plasma biomarkers of oxidative stress in humans]. An Sist Sanit Navar 2008, 31:259-280

49. García-Lafuente A, Guillamón E, Villares A, Rostagno MA, Martínez JA: Flavonoids as anti-inflammatory agents: implications in cancer and cardiovascular disease. Inflamm Res 2009, 58:537-552.

50. Liu RH: Health benefits of fruit and vegetables are from additive and synergistic combinations of phytochemicals. Am J Clin Nutr 2003, 78:5175-520S.

51. Mayne ST: Antioxidant nutrients and chronic disease: use of biomarkers of exposure and oxidative stress status in epidemiologic research. J Nutr 2003, 133(Suppl 3):933S-940S

52. Mazière C, Mazière JC: Activation of transcription factors and gene expression by oxidized low-density lipoprotein. Free Radic Biol Med 2009, 46:127-137.

53. Fuentes F, López-Miranda J, Sánchez E, Sánchez F, Páez J, Paz-Rojas E, Marin C, Gómez P, Jimenez-Pereperez J, Ordovas JM, Pérez-Jimenez F: Mediterranean and low-fat diets improve endothelial function in hypercholesterolemic men. Ann Intern Med 2001, 134:1115-1119.

54. Hermsdorff HHM, Zulet MA, Abete I, Martínez JA: Discriminated benefits of a Mediterranean dietary pattern within a hypocaloric diet program on plasma RBP4 concentrations and other inflammatory markers in obese subjects. Endocrine 2009, 36:445-451.

55. Shai I, Schwarzfuchs D, Henkin Y, Shahar DR, Witkow S, Greenberg I, Golan R, Fraser D, Bolotin A, Vardi H, et al: Weight loss with a lowcarbohydrate, Mediterranean, or low-fat diet. N Engl J Med 2008, 359:229-241

56. Hermsdorff HHM, Puchau B, Zulet MA, Martínez JA: Association of body fat distribution with proinflammatory gene expression in peripheral blood mononuclear cells from young adult subjects. OMICS 2010, 14:297-307.

57. Hermsdorff HHM, Zulet MA, Puchau B, Martínez JA: Central adiposity rather than total adiposity measurements are specifically involved in the inflammatory status from healthy young adults. Inflammation 2011, 34:161-170.

58. Bell HK, Bloomer RJ: Impact of serum estradiol on postprandial lipemia, oxidative stress, and inflammation across a single menstrual cycle. Gend Med 2010, 7:166-178

doi:10.1186/1743-7075-8-59

Cite this article as: Hermsdorff et al:: Dietary total antioxidant capacity is inversely related to central adiposity as well as to metabolic and oxidative stress markers in healthy young adults. Nutrition \& Metabolism $20118: 59$

\section{Submit your next manuscript to BioMed Central and take full advantage of:}

- Convenient online submission

- Thorough peer review

- No space constraints or color figure charges

- Immediate publication on acceptance

- Inclusion in PubMed, CAS, Scopus and Google Scholar

- Research which is freely available for redistribution

Submit your manuscript at www.biomedcentral.com/submit
C Biomed Central 